\title{
Reflecting Societal Values in Designing Flood Risk Management Strategies
}

\author{
Mark Adamson ${ }^{1, a}$, John O'Sullivan ${ }^{2}$ and Zeinab Bedri ${ }^{2}$ \\ ${ }^{1}$ Office of Public Works, Ireland \\ ${ }^{2}$ University College Dublin, Ireland
}

\begin{abstract}
In 2006, the Office of Public Works (OPW) began the National Catchment-based Flood Risk Assessment and Management (CFRAM) Programme through a series of pilot studies. A Multi-Criteria Analysis (MCA) Framework was developed through the pilot studies that integrated a number of objectives related to a wide range of potential impacts and benefits into the core of process of appraising and selecting suitable flood risk management measures for a given area or location, and then for prioritising national investments for different schemes and projects. This MCA Framework, that provides a systematic process of developing a non-monetised but numerical indicator of benefit and impact, has since been implemented nationally in the preparation of the Flood Risk Management Plans (FRMPs). A key feature of the MCA is that it should represent societal values. To this end, nationally representative quantitative research was undertaken to determine global weights that reflect the perceived importance of each of the objectives for reducing economic, social and environmental / cultural risks in flood management strategies. Saaty's Analytical Hierarchy Process (AHP), in conjunction with a pair-wise comparison of criteria relating to these risks, was utilised to determine weights. In excess of 1,000 structured interviews were completed where the relative importance of these objectives were assessed using a seven-point scale. The weighting given to each of the 13 specific objectives identified broadly followed expectations, with risk to people followed by risk to homes and properties being respectively the first and second most important, although some were given greater or less weighting than expected. The national application of the MCA Framework, using the weighted objectives based on this process, through the CFRAM Programme has generally lead to the identification of appropriate and, based on local consultation, acceptable options for each community.
\end{abstract}

\section{Background and Context}

Excess water management in Ireland has historically been focussed on drainage for the improvement of lands for agricultural production, and then more recently (since 1995) on structural flood protection schemes to reduce flood risk in urban areas. The assessment of which protection scheme would be most suitable for a community was based primarily on the economic benefitcost ratio, with environmental assessments undertaken in line with legislation to minimise environmental impacts, and public consultation undertaken to ensure that a proposed scheme would be acceptable to a community.

In 2003, a review of national flood risk management policy was commenced to reconsider the national approach to managing flood risk, in line with changing views nationally and a shift in the international paradigm. The review was undertaken by an Inter-Departmental Review Group that produced a report, setting out a wide range of recommendations, which was adopted by Government in September 2004 (OPW, 2004). Among the recommendations of the Report were:
- Minimising the national level of exposure to flood damages through the identification and management of existing, and particularly potential future, flood risks in an integrated, proactive and catchment-based manner,

- A greater level of importance attributed to nonstructural flood relief measures supported, where necessary, by traditional structural flood relief measures

- The comprehensive development of Flood Maps

- The development of Catchment Flood Risk Management Plans (FRMPs)

- That issues such as social and environmental impacts are considered in the planning of long-term management strategies and flood protection works

To implement the adopted policy, the Office of Public Works (OPW), appointed as the lead agency for flood risk management in Ireland, developed the Catchmentbased Flood Risk Assessment and Management (CFRAM) Programme. In 2005-2006, the OPW commenced pilot CFRAM projects to test the new process.

\footnotetext{
$\overline{{ }^{a} \text { Corresponding author: mark.adamson@opw.ie }}$
} 
The EU Directive on the Assessment and Management of Flood Risks (the 'Floods' Directive) came into force in November 2007 (EU, 2007). This requires Member States to undertake a Preliminary Flood Risk Assessment to identify areas of potentially significant flood risk, and then for these areas, prepare flood maps. The Directive then requires that Members States develop Flood Risk Management Plans (FRMPs) aimed at managing and reducing the flood risks to human health, the environment, cultural heritage and economic activity within the identified areas.

It can be seen that the 'Floods' Directive is aligned with and underpins the national flood policy adopted in 2004. In particular, the Directive reinforces the need to focus not just on economic impacts of flood events, but on a wider range of impacts including social, environmental and cultural.

\section{Option Appraisal: The Multi-Criteria Appraisal Framework}

The FRMPs need to set out a preferred set of measures for the long-term, sustainable management of flood risk for their area of coverage. An appraisal system is required to determine which measures are most appropriate for inclusion in the FRMPs. As set out above, this appraisal process was historically in Ireland based primarily on an economic benefit-cost ratio. In line with the national flood policy adopted, as supported by the 'Floods' Directive, this process had to change to reflect a wider range of benefits and potential impacts.

One option considered to meet this challenge was the monetisation of non-market benefits and impacts (such as through the ecosystem services approach) for the purposes of a multi-sectoral economic benefit - cost analysis. Significant progress has been made in recent years on the subject of determining economic values for cultural heritage and environmental resources, assets and services, for non-market social impacts, and for other non-market impacts or benefits. However, it was considered that there remained significant uncertainty in this area in terms of valuation, and alternative approaches also needed to be considered.

Under the Lee Pilot CFRAM Project, a Multi-Criteria Analysis (MCA) Framework was developed and tested as a means for appraising options for flood risk management measures to determine what the most suitable and appropriate measure might be for a particular area. The MCA represents a numerical, but non-monetised, method for selecting the most advantageous options, which is based on replacing economic values with societal values.

At the core of the MCA Framework are a set of objectives. These objectives form the criteria against which the options are appraised to determine how far the option goes towards meeting each objective, or indeed, if pursuing a given option would in fact be detrimental with regards to a particular objective. In operating the Framework, each option is scored (on a scale of +5 to -5 ) by the appraiser (typically a flood risk management professional) against each of the objectives, based on how far the option goes beyond meeting a 'basic requirement' towards meeting an 'aspirational target' that have both been defined for each objective. The 'basic requirement' is typically based on a no-change outcome, i.e., no detrimental nor positive impacts, whereas the 'aspirational target' is generally phrased as the elimination of the risk that is relevant to the objective (i.e., reduction of the risk to zero), or the full achievement of another benefit, such as for an environmental objective. It is rare that an 'aspirational target' would be fully achieved. Where an option increases a risk, or is detrimental to an objective, then a negative score is assigned, with a '-999' score being assigned to remove the option from further consideration if the increase in risk or detrimental impact is deemed to be unacceptable.

The scores for an option against each objective is multiplied by the Global and Local Weightings (see below) and then summed across the objectives to determine the overall 'MCA Benefit' score, which represents the overall net benefit and impact of the option across the full range of objectives. Options are costed in terms of implementation, maintenance, operation, etc. to determine the whole-life option cost. The 'MCA Benefit' to cost ratio hence represents the overall net benefit, again across the range of objectives, per euro spent that the option would provide if implemented. The option with the greatest 'MCA Benefit' to cost ratio is identified as the preferred option for the area, although this conclusion clearly needs to be reviewed against professional judgement to avoid system errors, and is subject to public consultation.

\subsection{Defining the flood risk management objectives}

For the purposes of the Pilot CFRAM Projects, the set of Objectives was developed on the basis of professional judgement only, albeit as advised by stakeholder groups. However, for the National CFRAM Programme (covering all areas of potentially significant risk across the country), it was determined that, as the Objectives were critical to the selection of measures to be pursued through the FRMPs, and for the process to conform with the core concept of 'societal value', the Objectives must be subject on democratic review. The Objectives were hence discussed in a national stakeholder group and put out to national public consultation (Oct. - Nov. 2014), and were amended as appropriate to reflect the submissions received.

The final set of objectives as used relate to a reduction in the risk, or providing benefits, to:

- Society (risk to human life and health, risk to vulnerable properties, risk to social infrastructure and amenity, risk to local employment)

- The Economy (economic risk (i.e., risk to properties), risk to utility and transport infrastructure and risk to agricultural production)

- The Environment and Cultural Heritage (Water Framework Directive objectives, Natura 2000 sites and our flora and fauna, risk to fisheries, risk to landscape character and visual amenity, risk to 
features, institutions and collections of cultural heritage importance)

Technical objectives were also set relating to health and safety, operational robustness and adaptability to climate and other potential future changes.

\section{Determining weightings for the objectives}

As set out above, the MCA is based on the representation of societal value. Notwithstanding this, due consideration is required for each of the three groups of potential benefits and impacts, namely those to society, to the economy and to the environment and our cultural heritage. These groups, that make up the three UN pillars of sustainable development, are the focus for flood risk management and reduction as quoted in the 'Floods' Directive without prioritising any one over the others. It was not considered appropriate to consult on the relative weightings of the three core categories for the purposes of application of the MCA Framework, as it is foreseeable that the outcome of such a consultation would be that a significantly reduced weighting would be given to the Environmental and Cultural Heritage group relative to the Social and Economic group, which could undervalue the objectives in this group, and so each of these groups were given equal weighting overall.

Having established the objectives and their wording, we also need to recognise that society would not value each of the objectives within each group (economy, society and environment/cultural heritage) equally. The weightings assigned across the range of objectives within each group must represent societal priorities. Under the Lee Pilot CFRAM Project, these weightings were determined by professional judgement, informed by stakeholder group opinion. For the National CFRAM Programme however, it was considered that this approach was insufficient and that a greater link needed to be made with public opinion. The OPW therefore decided to determine the Global Weightings through a scientificallybased evaluation of the value society attached to each objective, as established through consultation.

\subsection{Methodology or determining the weightings}

Determining global weightings was based on the structured technique in Saaty's (Saaty, 1990, 2003) Analytical Hierarch Process (AHP). The AHP represents a multi-criteria decision making approach where the relative importance of sets of criteria or objectives is compared in a pair-wise analysis. The objectives considered in this study are consistent with those determined for use in the MCA framework as above, but these however are now considered in the context of the structured hierarchy of principle and sub objectives as in Figure 1, where the 'goal' is at the highest level of the hierarchy. The study 'goal' was to determine global weights that reflect the perceived importance of each of the objectives for reducing economic, social and environmental / cultural risks in flood management strategies and as such, the intermediate levels of the hierarchy consist of the groups of objectives, with the associated objectives at the lowest level of the hierarchy.

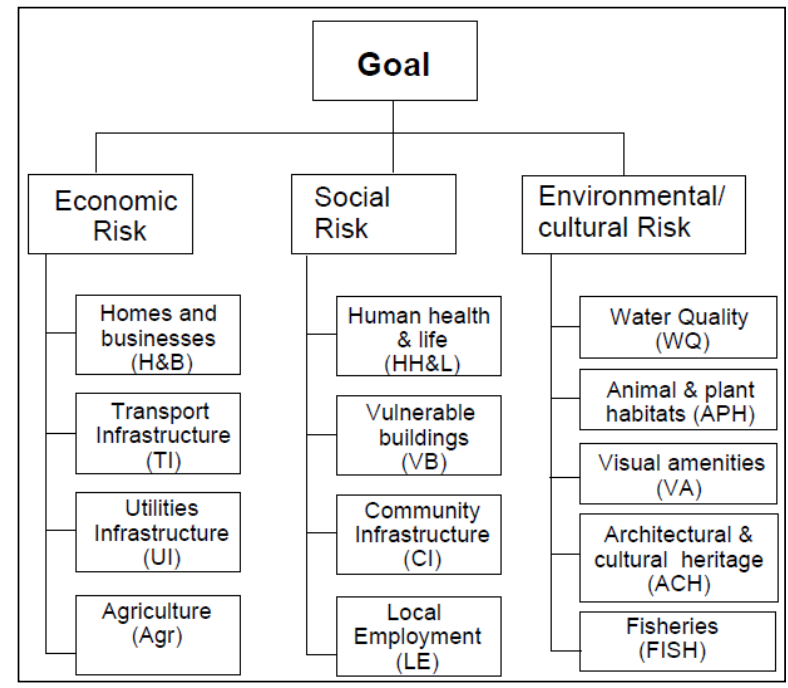

Figure 1. Decision hierarchy utilised in study

\subsection{Data collection}

The public consultation exercise for data collection involved a country-wide (65 locations) questionnaire survey from the 23rd April to 6th May 2015 completed through 1003 face-to-face interviews using CAPI (Computer Assisted Personal Interviewing). Interviews were conducted by trained members of the Behaviour \& Attitudes field force working under supervision. Behaviour and Attitudes (www.banda.ie) is an independent market research agency that was engaged by OPW for this study. The sample was quota controlled in terms of gender, age, social class, region and area of residence to match the known population statistics (Central Statistics Office, 2016). As such, the national statistic for citizens who have been subjected to, or experienced flooding, is reflected in the sample. The questionnaire, developed jointly by University College Dublin (UCD) and OPW, contained closed-form, precise and unambiguous questions that were formulated to minimise misunderstanding. Prior to its full implementation, the questionnaire was tested from the 23rd to the 30th September 2014 through 24 pilot interviews conducted in the provincial towns of Cork and Athlone (6 no. interviews in each) and Ireland's capital city, Dublin (12 no. interviews). The broad demographic profile of respondents who participated in the pilot is summarised in Table 1.

\begin{tabular}{|c|c|c|c|}
\hline $\begin{array}{c}\text { No. of } \\
\text { Interviews }\end{array}$ & Gender & Age & Social Class \\
\hline 12 & Male & $\leq 35$ & ABC1 \\
\hline 12 & Female & $>35$ & C2DE \\
\hline
\end{tabular}

Table 1. Demographic characteristics of 24 pilot interviews

Questionnaires were divided in sections that dealt with pair-wise comparison of the flood risk management 
objectives in Figure 1. Standard demographic data relating to the respondent was also collected.

Section 1 of the questionnaire compared the four objectives, namely the minimising of risks to (i) homes and businesses; (ii) transport infrastructure (roads, railways, etc.); (iii) utility infrastructure (including electricity, telecommunications and water); and (iv), agriculture (including animals and farmland) under the primary objective of minimising economic risk. Similarly, Section 2 and 3 of the questionnaire requested that respondents provide their opinions as to the relative importance of minimising the risks in the lowest level of the Figure 1 hierarchy under the primary objectives of minimising both social risk and environmental and cultural risk.

The application of a pairwise comparison and the use of Saaty's AHP (e.g. Cardona, 2006; Bjarnadottir et al., 2011; Kienberger et al., 2009) is a suitable approach for this analysis as it rejects the simplification of parameters in order to suit quantitative or monetary analysis (e.g. cost benefit analysis). The method of AHP involves comparing criteria in a pair-wise fashion in their strength of influence on a single factor, in this case, the benefits / impacts of flood risk management. Clustering common criteria or objectives (as in Figure 1) allows potentially for weights to be attributed to both the groups of objectives and individual objectives (Saaty and Vargas, 1982). Saaty noted that the ability to make qualitative decisions can be typically characterised by five attributes of equal, weak, strong, very strong and absolute. In this context, numbers on a nine-point scale representing these attributes (even numbers represent compromise) are commonly applied. However, for the purpose of simplification in this study, a seven-point scale (Table 2) was deemed most suitable. Saaty's AHP required that data from responses collected using the 7-point scale in the questionnaire be transformed. This was done in accordance with the scales in Table 2.

Limitations of the AHP include the use of a limited semantic scale which Saaty assumes can be directly related to a ratio scale (Saaty and Kearns, 1985; Saaty and Vargas, 1982). Others however, believe that this scale inflicts unnatural restrictions on judgements, resulting in reduced precision and comprehensibility of the method (Freeling, 1983; Dyer, 1990). Further to this, Dyer (1990) states that the AHP process is flawed as a procedure as the rankings produced are arbitrary. However, the method is useful for this type of research where quantitative valuations and comparisons are inappropriate.

\subsection{Data analysis}

Each section of the questionnaire corresponding to the second tier hierarchy objectives in Figure 1 was analysed separately. Based on the individual questionnaire responses, numbers on the seven-point scale representing the attributes in Table 2 were inserted in a matrix and the eigenvector with the largest eigenvalue was found. The eigenvector represents the importance ordering and the eigenvalue is a measure of the consistency of the judgement. Real world problems are rarely consistent and inconsistent matrices can therefore occur. For example, considering a $3 \times 3$ matrix, if factor $A$ is quantified as five times more preferable than factor B, which is in turn twice as preferable as factor $\mathrm{C}$, a perfectly consistent matrix will exist if factor $\mathrm{A}$ is ten times more preferable than factor $\mathrm{C}$. Inconsistency can arise if factor $\mathrm{A}$ is judged to be just six times more preferable than factor $\mathrm{C}$ for example, or indeed if factor $\mathrm{C}$ is considered preferable to factor A. Consistency does not need to be perfect, providing there is enough consistency to uphold logic (Saaty, 1990). Overall consistency judgements are measured using a consistency ratio $(\mathrm{CR})$ which is the ratio of a consistency index $(\mathrm{CI})$ to the average consistency index of randomly generated $n$ $\mathrm{x} \mathrm{n}$ reciprocal matrices (RI) according to Equation 1.

$$
\mathrm{CR}=\frac{\mathrm{CI}}{\mathrm{RI}}
$$

CI can be calculated using the largest eigenvalue $\lambda_{\max }$ in Equation 2, where $\mathrm{n}$ is the order of the matrix.

$$
\mathrm{CI}=\frac{\lambda \max -\mathrm{n}}{n-1}
$$

As part of the analysis, Consistency Ratios (CR) were computed for the response matrices. The $\mathrm{CR}$ is a measure of how consistent the judgements have been relative to large samples of purely random judgements. While a consistency ratio of less than 0.1 is considered desirable, this is often difficult to achieve because of the complexity of the compared elements and the limited ability of human thinking. Therefore, for the current analysis a consistency ratio threshold of 0.2 was used to maximise the number of logical responses included in the analysis. Two options for dealing with consistency ratios greater than threshold values are commonly adopted in scientific studies. The first involves transforming the inconsistent matrix by asking respondents to reconsider their judgements by until consistency is approached (Saaty, 2003). The second involved removing the inconsistent matrix from the analysis. The second option was chosen for this study and matrices with CR $>0.2$ were excluded (Apostolou and Hassell, 1993; Andrew et al., 2005).

The use of the geometric mean was used to aggregate individual judgements into a single representative judgement for the entire group. Use of the arithmetic mean was also considered, but this is more commonly applied in exercises that rely on 'expert' opinions.

\subsection{Results}

The individual sections of the questionnaire, dealing with respondent's views on the role of flood risk management in minimising economic, social and environmental/ cultural risks respectively, were analysed separately. Using the AHP, the calculated weightings for 
the objectives relating to each group of objectives (Section 1, 2 and 3) sum to unity and the actual weighting, relative to unity, reflects the perceived importance of the objective.

$\begin{aligned} & \text { Section 1: minimising Economic risk (pairwise comparison between the two economic criteria: homes \& businesses and } \\
& \text { transport infrastructure) }\end{aligned}$
\begin{tabular}{|l|c|c|c|c|c|c|c|}
\hline Minimise risk to homes and businesses & \multicolumn{2}{|c|}{$\begin{array}{c}\text { Minimise risk to transport infrastructure } \\
\text { (e.g. roads, railways) }\end{array}$} \\
\hline Scale & $\begin{array}{c}\text { Very much } \\
\text { more } \\
\text { important }\end{array}$ & $\begin{array}{c}\text { Much more } \\
\text { important }\end{array}$ & $\begin{array}{c}\text { Slightly } \\
\text { more } \\
\text { important }\end{array}$ & $\begin{array}{c}\text { Of equal } \\
\text { importance }\end{array}$ & $\begin{array}{c}\text { Slightly } \\
\text { more } \\
\text { important }\end{array}$ & $\begin{array}{c}\text { Much more } \\
\text { important }\end{array}$ & $\begin{array}{c}\text { Very much } \\
\text { more } \\
\text { important }\end{array}$ \\
\hline Ques & 1 & 2 & 3 & 4 & 5 & 6 & 7 \\
\hline Saaty & 7 & 5 & 3 & 1 & $1 / 3$ & $1 / 5$ & $1 / 7$ \\
\hline
\end{tabular}

Table 2. Example conversion of questionnaire (Ques) scale to Saaty's scale

\subsubsection{Minimising economic risk}

Table 3 presents results of the analysis of Section 1 of the questionnaire that compares the four objectives (left column in Figure 1) for minimising the economic risk of flooding. The results illustrate that for $\mathrm{CR} \leq 0.2$, circa. $60 \%$ of the 1,003 responses are included. The weighting of 0,41 indicates that minimising the risk to homes and businesses (H\&B) was the most important criterion for the public in minimising the economic risk of flooding. Minimising the risk to agriculture (Agr) and utilities infrastructure (UI) and agriculture (Agr) were considered to be of lesser importance, as reflected in weightings of 0.226 and 0.201 respectively. Minimising the risk to transport infrastructure (TI) with a weighting of 0.163 was considered the least important criterion.

\begin{tabular}{|c|c|c|c|c|}
\hline No. of & \multicolumn{4}{|c|}{ Calculated Weightings } \\
\cline { 2 - 5 } $\begin{array}{c}\text { analysed } \\
\text { responses } \\
(\mathrm{CR} \leq 0.2)\end{array}$ & H \& B & TI & UI & Agr \\
\hline 594 & 0.410 & 0.163 & 0.226 & 0.201 \\
\hline
\end{tabular}

Table 3. Calculated weightings of the objectives for minimising economic risk

\subsubsection{Minimising social risk}

Table 4 shows the weightings given by the questionnaire interviewees for the relative importance of four criteria (middle column of Figure 1) for minimising the social risks of flooding; human health and life (HH\&L), vulnerable buildings (VB), community infrastructure (CI), and local employment (LE). Approximately $62 \%$ of responses had acceptable CR values and were included in the analysis.

\begin{tabular}{|c|c|c|c|c|}
\hline \multirow{2}{*}{$\begin{array}{c}\text { No. of } \\
\text { analysed } \\
\text { responses } \\
(\mathrm{CR} \leq 0.2)\end{array}$} & \begin{tabular}{c} 
HH \& \\
\cline { 2 - 5 }
\end{tabular} & VB & CI & LE \\
\hline 625 & 0.466 & 0.283 & 0.143 & 0.109 \\
\hline
\end{tabular}

Table 4. Calculated weightings of the objectives for minimising social risk
The risk minimisation to human health and life was clearly prioritised as evidenced by the calculated weighting of 0.466 . Minimising the risk to vulnerable buildings (e.g. hospitals, care homes etc.) was deemed to be of somewhat less importance but this was still considered a more important criterion than the reduction of risk to community infrastructure (e.g. schools and community centres) and local employment (e.g. local businesses, tourist attractions etc.) to which weightings of 0.143 and 0.109 respectively determined.

\subsubsection{Minimising environmental / cultural risk}

The relative importance of the five criteria for minimising the environmental and cultural risk of flooding are presented in Table 5. The five criteria are in the right side column of Figure 1 and include minimising risk to the water quality of rivers, lakes and sea (WQ), minimising the risk to protected animals and habitats $(\mathrm{APH})$, minimising the risk to visual amenities such as landscapes, urban settings and scenic views (VA), minimising the risk to features of architectural and cultural heritage (e.g. historic sites and museums) $(\mathrm{ACH})$ and minimising the risk to fisheries (FISH).

\begin{tabular}{|c|c|c|c|c|c|}
\hline \multirow{2}{*}{$\begin{array}{c}\text { No. of } \\
\text { analysed } \\
\text { responses } \\
(\mathrm{CR} \leq 0.2)\end{array}$} & WQ & APH & VA & ACH & FISH \\
\cline { 2 - 6 } & & & & & \\
\hline 651 & 0.283 & 0.256 & 0.128 & 0.121 & 0.211 \\
\hline
\end{tabular}

Table 5. Calculated weightings of the objectives for minimising environmental/ cultural risk

Data indicates that setting the $\mathrm{CR}$ ratio to 0.2 includes circa. $65 \%$ of the responses. The weightings determined for the five criteria demonstrate that priority for respondents lies with minimising the risk to water quality (WQ), and the protection of animals and habitats (APH). Minimising the risk to fisheries was considered to be of lesser importance, while minimising the risk to visual amenities and features of architectural and cultural heritage were deemed least important by the survey respondents. 
The objectives, and the final global weightings assigned to each objective, as subsequently applied in the MCA Framework under the National CFRAM Programme is provided in Table 6. These have been determined by scaling the percentage weightings determined through the data analysis up to a total of 60 , and rounding (within this total) to the nearest round whole number.

\begin{tabular}{|l|l|c|}
\hline Criteria & Objective & Weighting \\
\hline Social & Minimise risk to human health and life of residents & 27 \\
\cline { 2 - 3 } & Minimise risk to high vulnerability properties & 17 \\
\cline { 2 - 3 } & Minimise risk to social infrastructure and amenity & 7 \\
\cline { 2 - 3 } & Minimise risk to local employment & 24 \\
\hline \multirow{5}{*}{$\begin{array}{l}\text { Economic } \\
\text { Cultural }\end{array}$} & Minimise economic risk & 10 \\
\cline { 2 - 3 } & Minimise risk to transport infrastructure & 14 \\
\cline { 2 - 3 } & Minimise risk to utility infrastructure & 12 \\
\cline { 2 - 3 } & Minimise risk to agriculture & $\begin{array}{l}\text { Provide no impediment to the achievement of water body objectives and, if possible, contribute } \\
\text { to the achievement of water body objectives. }\end{array}$ \\
\cline { 2 - 3 } & $\begin{array}{l}\text { Avoid detrimental effects to, and where possible enhance, Natura 2000 network, protected } \\
\text { species and their key habitats, recognising relevant landscape features and stepping stones. }\end{array}$ & 10 \\
\cline { 2 - 3 } & $\begin{array}{l}\text { Avoid damage to or loss of, and where possible enhance, nature conservation sites and protected } \\
\text { species or other know species of conservation concern. }\end{array}$ & 5 \\
\cline { 2 - 3 } & $\begin{array}{l}\text { Maintain existing, and where possible create new, fisheries habitat including the maintenance or } \\
\text { improvement of conditions that allow upstream migration for fish species. }\end{array}$ & 13 \\
\cline { 2 - 3 } & $\begin{array}{l}\text { Protect, and where possible enhance, visual amenity, landscape protection zones and views into / } \\
\text { from designated scenic areas within the river corridor. }\end{array}$ & 8 \\
\cline { 2 - 3 } & $\begin{array}{l}\text { Avoid damage to or loss of features, institutions and collections of cultural heritage importance } \\
\text { and their setting }\end{array}$ & 8 \\
\hline
\end{tabular}

Table 6. Objectives and the final global weightings

\subsection{Recognising local values and context}

While the overall societal value is fundamental to the validity of the MCA process being applied under the National CFRAM Programme in Ireland, recognition is also required of the local context and values in the particular community or area where a flood risk management measure is being proposed.

To provide for this important dimension, the MCA includes a Local Weighting as well as a Global Weighting to be applied to the score assigned for each objective. The determination of the Local Weighting is, in the first instance, determined by the relevance of the objective within the local context. For example, the objective relating to transport infrastructure may be less relevant if no major transport routes or infrastructure is at risk, and short diversion routes are available and no properties are at risk from isolation in the event that local routes are closed due to flooding. However, these factors, which are determined remotely, may not fully reflect local values and so public consultation has also been undertaken at a local level through public consultation days within each community to determine which objectives are most relevant to people locally. Feedback from this local consultation helps determine the Local Weightings and hence the influence of each objective on the determination of the most appropriate measure for that community.
Ultimately, the local community have a final say as the proposed measures, as determined through the MCA process, and also the Draft FRMPs are both subject to further public consultation, including local consultation events. The OPW does not impose protection or risk management measures on a community against their will, and public engagement, undertaken locally, is an important influence on the identification and development of suitable approaches to flood risk management for a given community. While public engagement has been used to determine the objectives and the weightings assigned to the objectives within the MCA Framework, the Framework remains a decisionsupport tool and not a decision-making tool. If the above processes leads to the recommendation of a measure or set of measures that the community doesn't approve of or agree with, then further consultation and analysis is undertaken to develop a revised measure or measures.

\section{Conclusions}

This paper has described the background as to why an MCA approach has been developed and implemented in Ireland for the determination of appropriate flood risk management measures. Flood risk management objectives from the core of this MCA 
approach that is intended to represent societal value, and hence have been determined based on public consultation.

A public consultation exercise was conducted in order to determine the relative importance of various flood risk management objectives and assign relative weightings to these objectives. A questionnaire survey developed jointly by UCD and OPW was used for data collection. A pilot study of 24 samples was first collected and the feedback from the pilot study was then used to improve the main questionnaire in which just over 1000 structured interviews were conducted with members of the public. The door-to-door interviews were conducted by Behaviour and Attitudes Ltd. on behalf of the OPW. The questionnaire included a pairwise comparison of the various flood risk management objectives along with some demographic information. The pairwise comparisons in the questionnaire were analysed using Saaty's Analytical Hierarch Process (AHP) (Saaty, 1990 and 2003) to identify and weight the objectives deemed to be most important by the public.

The results of the analysis revealed that minimising the risk of flooding to homes and businesses was deemed the most important economic criterion. With regards to minimising the social risk of flooding, the public agreed that the protection of human health and life was considered a priority. Also, and from an environmental perspective, minimising the risk to the water quality of rivers, lakes and seas ranked most highly.

The MCA Framework, with the objectives and weightings determined as above, has been used to examine potential flood risk management measures for nearly 300 communities around Ireland. The process has generally produced sensible outcomes in terms of preferred measures, from a professional flood risk managers perspective, and these proposed measures, that have been set out in a national set of Draft FRMPs, have also generally meet with local support during various stages of public consultation and engagement. As such, it is concluded that the MCA Framework, and the approach taken to determine the objectives and weightings for the objectives, has been appropriate and successful for the National CFRAM Programme. Future use may however require review to ensure that the objectives and weightings used remain valid.

\section{References}

1. OPW (2004) Report of the Flood Policy Review Group (http://www.opw.ie/en/floodriskmanagement/)

2. EU (2007) Directive on the Assessment and Management of Flood Risks [2007/60/EC]

3. Saaty, T. L. (1990) How to make a decision: The Analytic Hierarchy Process. European Journal of Operational Research, 48, 9-26.
4. Saaty, T. L. (2003) Decision-making with the AHP: Why is the principal eigenvector necessary. European Journal of Operational Research, 145, 85-91.

5. Central Statistics Office (2016) Irish national census data http://www.cso.ie/. Accessed January 2016.

6. Cardona, O. D. (2006) A system of indicators for disaster risk management in the Americas. IN BIRKMANN, J. (Ed.) Measuring vulnerability to hazards of natural origin: towards disaster resilient societies. Tokyo, UNU Press.

7. Bjarnadottir, S., Li, Y. \& Stewart, M. (2011) Social vulnerability index for coastal communities at risk to hurricane hazard and a changing climate. Natural Hazards, 59, 1055-1075.

8. Kienberger, S., Lang, S. \& Zeil, P. (2009) Spatial vulnerability units - expert-based spatial modelling of socio-economic vulnerability in the Salzach catchment, Austria. Natural Hazards and Earth System Sciences, 9, 767-778.

9. Saaty, T. L. \& Vargas, L. G. (1982) The Logic of Priorities: Applications in Business, Energy, Health and Transportation, Pittsburgh, PA, RWS Publications.

10. Saaty, T. L. \& Kearns, K. P. (1985) Analytical Planning: The Organisation of Systems, Pittsburgh, PA, RWS Publications.

11. Freeling, A. (1983) Belief and Decision Aiding. PhD Thesis. University of Cambridge.

12. Dyer, J. S. (1990) Remarks on the Analytic Hierarchy Process. Management Science, 36, 249258.

13. Apostolou, B. \& Hassell, J. M. (1993) An empirical examination of the sensitivity of the analytic hierarchy process to departures from recommended consistency ratios. Mathematical and Computer Modelling, 17, 163-170.

14. Andrew, T. N., Rahoo, P. \& Nepal, T. (2005) Enhancing the selection of communication technology for rural telecommunications: $A n$ analytic hierarchy process model. International Journal of Computers, Systems and Signals, 6, 2634. 